\title{
Shared decision-making experienced by Canadians facing health care decisions: a Web-based survey
}

\author{
Julie Haesebaert MD PhD, Rhéda Adekpedjou MD MPH, Jordie Croteau MSc, \\ Hubert Robitaille PhD, France Légaré MD PhD
}

\section{Abstract}

Background: Despite health policy that promotes shared decision-making, it is not yet the norm in clinical practice. We aimed to assess how much shared decision-making Canadians experienced in health-related decisions in 2017.

Methods: We conducted a cross-sectional online survey in January 2018 with a Web-based panel of Canadians representing all 10 provinces. We assessed their involvement in health-related decisions made with a health care professional over the previous year by asking about 1) discussion of choice of treatment or care plan, 2) presentation of advantages and disadvantages, 3) exploration of ideas and preferences, 4) discussion of preferred option and 5) match between preferred and actual level of participation. We computed an average shared decision-making score (range 1 [never] to 5 [always]). We presented characteristics of participants and responses using descriptive statistics and explored variations across sociodemographic factors, jurisdictions, geographical areas and care settings (home care or not) using multivariate weighted regressions.

Results: Of the 1591 participants surveyed, 1010 (63.5\%) reported receiving health care in the previous 12 months. The mean of the average shared decision-making score was 2.25/5 (standard deviation [SD] 1.16). After weighting, $42.8 \%$ of respondents reported that their health care professional often or always mentioned that they had a choice of treatment or care plan, $45.4 \%$ reported that advantages and disadvantages were often or always presented, 38.8\% reported that they were often or always asked for their ideas or preferences, $40.2 \%$ reported that they were often or always asked about their preferred option, and $54.1 \%$ stated that their level of participation in decision-making often or always matched their preferred level of participation. Increasing age, rural setting, living in the province of Quebec and not being white significantly decreased the level of shared decision-making experienced. Older respondents (age $\geq 65 \mathrm{yr}$ ) receiving home care reported the least shared decision-making (mean score 1.7 [SD 0.5]).

Interpretation: Canadians in all 10 provinces experienced a low degree of shared decision-making in 2017, with variations across sociodemographic factors, jurisdictions, care settings and geographical areas. Further efforts to foster implementation of shared decision-making are needed and should take these variations into account.

anadians need support in health-related decisionmaking. ${ }^{1}$ More than half of Canadians experience decisional conflict after having made a complex health decision. ${ }^{1}$ Many of the decisions patients face present multiple options, there is incomplete or conflicting evidence about possible outcomes, and expectations are often unrealistic. ${ }^{1,2}$ Shared decision-making is a process whereby health care professionals and patients work jointly to make health care choices, considering best clinical evidence as well as patients' values and preferences. ${ }^{3}$ It constitutes a key component of patient-centred care ${ }^{4}$ and results in better health care choices, with demonstrated benefits and less practice variation. ${ }^{5}$ Several reasons, such as time constraints, have been raised to explain a lack of implementation of shared decision-making in daily clinical practice. ${ }^{6}$ However, most reasons are not evidence-based and are often based on misconceptions. ${ }^{7}$ Although previous surveys and studies have reported on the level of shared decision-making in diverse health care settings, ${ }^{8,9}$ we know little from a population-based perspective in Canada. Therefore, we aimed to assess how much shared decision-making Canadians experienced in health-related decisions and to explore variations across sociodemographic factors, jurisdictions and care settings.

\section{Competing interests: None declared.}

This article has been peer reviewed.

Correspondence to: France Légaré, France.Legare@mfa.ulaval.ca CMAJ Open 2019. DOI:10.9778/cmajo.20180202 


\section{Methods}

\section{Study design}

We conducted a cross-sectional online survey of Canadians from the 10 provinces from Jan. 22 to Jan. 25, 2018, using a pan-Canadian Web panel (Léger Marketing). We used the Checklist for Reporting Results of Internet E-Surveys (CHERRIES) to guide reporting of results. ${ }^{10}$

\section{Participants and recruitment}

The population studied consisted of Canadian citizens aged 18 years or more from all 10 provinces (no panel participants came from the territories) enrolled in Léger Marketing's panCanadian Web panel of 400000 citizens. Panellists are recruited through a multifaceted strategy involving probabilistic telephone and email contacts, as well as social media advertising, word of mouth and snowball sampling to cover a broad range of sociodemographic profiles. The use of the Internet enables surveys to reach almost all strata of the population: a recent survey in the province of Quebec revealed that $90 \%$ of households were connected to the Internet. ${ }^{11}$ The main sociodemographic characteristics of the 400000 panellists are presented in Appendix 1 (available at www.cmajopen.ca/ content/7/2/E210/suppl/DC1). Random samples from this panel are solicited weekly to voluntarily participate in surveys. For the present survey, stratified simple random sampling was conducted to invite 10000 panellists to participate. Stratification of Canadian provinces, age and sex based on 2016 Canadian census data was applied to ensure a representative sample of the population. Panellists who reported that they had received health care in the previous 12 months were eligible for the study. Participants did not know they would be surveyed on shared decision-making in health care and related issues.

\section{Questionnaire development}

The questions on shared decision-making in health-related decisions were part of a larger survey called Omnibus Survey Canada (OMNICAN), a national multitopic weekly survey conducted by Léger Marketing among a random sample of their Web panellists. The OMNICAN questions change each week, depending on the firm's clients. We inserted questions on shared decision-making into one of these weekly surveys. The survey included a question on language preference (English or French), a section on sociodemographic characteristics, and 14 sections on a variety of topics proposed by other clients of the OMNICAN survey. The eighth section was on shared decision-making; the other sections were unrelated to health. The full questionnaire took about 15 minutes to complete. The full questionnaire is presented in Appendix 2 (available at www.cmajopen.ca/content/7/2/E210/suppl/DC1).

Sociodemographic characteristics elicited included age, sex, marital status, care setting, geographical area, ethnicity, level of education, employment status, total family income, province of residence and first language.

To our knowledge, no standardized questionnaire is available to measure shared decision-making using a generic primary care approach and applicable to population-level surveys. We thus developed our own questions, guided by the scientific literature ${ }^{12-14}$ and constructs commonly used in the field of shared decision-making, ${ }^{15,16}$ to target the main components of shared decision-making. We measured shared decision-making using 5 questions focusing on participants' health care experiences over the previous 12 months. Regarding the decisions they had made about a treatment/care plan during that period, participants were asked whether their health care professional (e.g., doctor, nurse, pharmacist, physiotherapist, nutritionist) 1) mentioned that they had a choice, 2) presented the advantages and disadvantages of the available options, 3) asked for their ideas and preferences and 4) asked which option they preferred, and 5) whether their level of participation in decisionmaking matched their preferred level of participation. Participants indicated their responses on a 5-point Likert scale from 1 ("Never") to 5 ("Always"), with the additional option of "I don't know/I prefer not to answer." The shared decision-making questionnaire was written in English and then translated by a professional translator into French. The full questionnaire was pilot-tested for navigability and comprehensibility among a random sample of 80 panellists before data collection.

\section{Data collection}

A link to the Web-based survey was sent by email to the participants. Respondents logged on to the questionnaire using their panel membership account, which allowed only 1 questionnaire validation per member to prevent duplicate entries by the same user. Each question was presented on a separate Web page. Questions appeared in the same order for all participants. Participants had to respond to all questions to validate the questionnaire. Respondents were not able to go backward to review and/or change their answers. A \$1 incentive was offered for completing the survey, and participants had the choice to keep it or to give it to a charitable organization.

\section{Sample size}

The targeted sample size for the full survey was 1591 participants. A probabilistic sample of this size would ensure a $2.5 \%$ margin of error for estimates with a $95 \%$ confidence level. The survey closed automatically when the target sample of 1591 respondents was reached.

\section{Statistical analysis}

Respondents who declared that they had received health care in the previous 12 months were included in the analysis. To ensure respondents were representative of residents of the 10 Canadian provinces aged 18 years or more, we weighted the data to Canadian census targets for age, sex, region and language based on distributions reported in the 2016 Canadian census. We performed all descriptive statistics and statistical tests with the weighting variable through complex samples analysis using R 3.3.0 (Survey package, version 3.33-2, R Foundation for Statistical Computing). 
The first step of the analysis consisted in exploring the dimensionality of the questionnaire. Factorial analysis included the 5 shared decision-making items to assess the validity of aggregating the 5 questions into 1 unique score. Based on the eigenvalues of the correlation matrix, this analysis detected only 1 factor in the data. Therefore, we computed a mean score from the 5 items. The average score ranged from 1 to 5 , with higher values reflecting a higher degree of shared decision-making. In the subsequent analyses, we applied the same strategy for each of the 5 items and for the average score as dependent variables scoring from 1 to 5 . We first conducted bivariate analysis of variance for each item, with the sociodemographic characteristics (age, sex, marital status, member of household receiving home care, geographical area, ethnicity, level of education, employment status, total family income, province of residence and first language) as independent variables. We then conducted multiple regression analysis for each item including all independent variables simultaneously and then applying a backward model selection using the average Wald statistic $p$ value with a threshold of 0.05 ; variables with at least 1 category presenting a $p$ value $<0.05$ remained in the model for the last step. We conducted a subgroup analysis of participants who answered "yes" to the question "Are you or is a household member receiving home care services for a health problem?" We conducted multiple regression analysis for the 5 items and the average score, including age, geographical area, province and ethnicity as independent variables.

\section{Ethics approval}

The Research Ethics Board of the Centre intégré universitaire de santé et de services sociaux de la Capitale-Nationale stated that no ethics committee approval was needed since the project was conducted in accordance with survey ethics. The survey was conducted in accordance with the Canadian Personal Information Protection and Electronic Documents Act and the Marketing Research and Intelligence Association's Charter of Respondent Rights. Respondents gave their consent to participate in the study by answering the questions.

\section{Results}

\section{Participants}

Figure 1 shows participant selection. Considering all potentially eligible participants who clicked on the link to visit the survey as unique survey visitors, the view rate was $17.2 \%$ $(1725 / 10000)$, and the participation rate was $92.2 \%$ $(1591 / 1725)$. Of the 1591 participants surveyed, 1010 $(63.5 \%)$ had received health care services during the previous 12 months. After weighting, $53.8 \%$ were women, $41.3 \%$ were aged 55 years or more, $33.1 \%$ lived in Ontario, and $30.4 \%$ lived in Quebec (Table 1). A total of 90 respondents $(8.9 \%)$ reported that they or a member of their household were receiving home care, similar to the 2016 Statistics Canada estimate of the proportion in the Canadian population as a whole. ${ }^{17}$

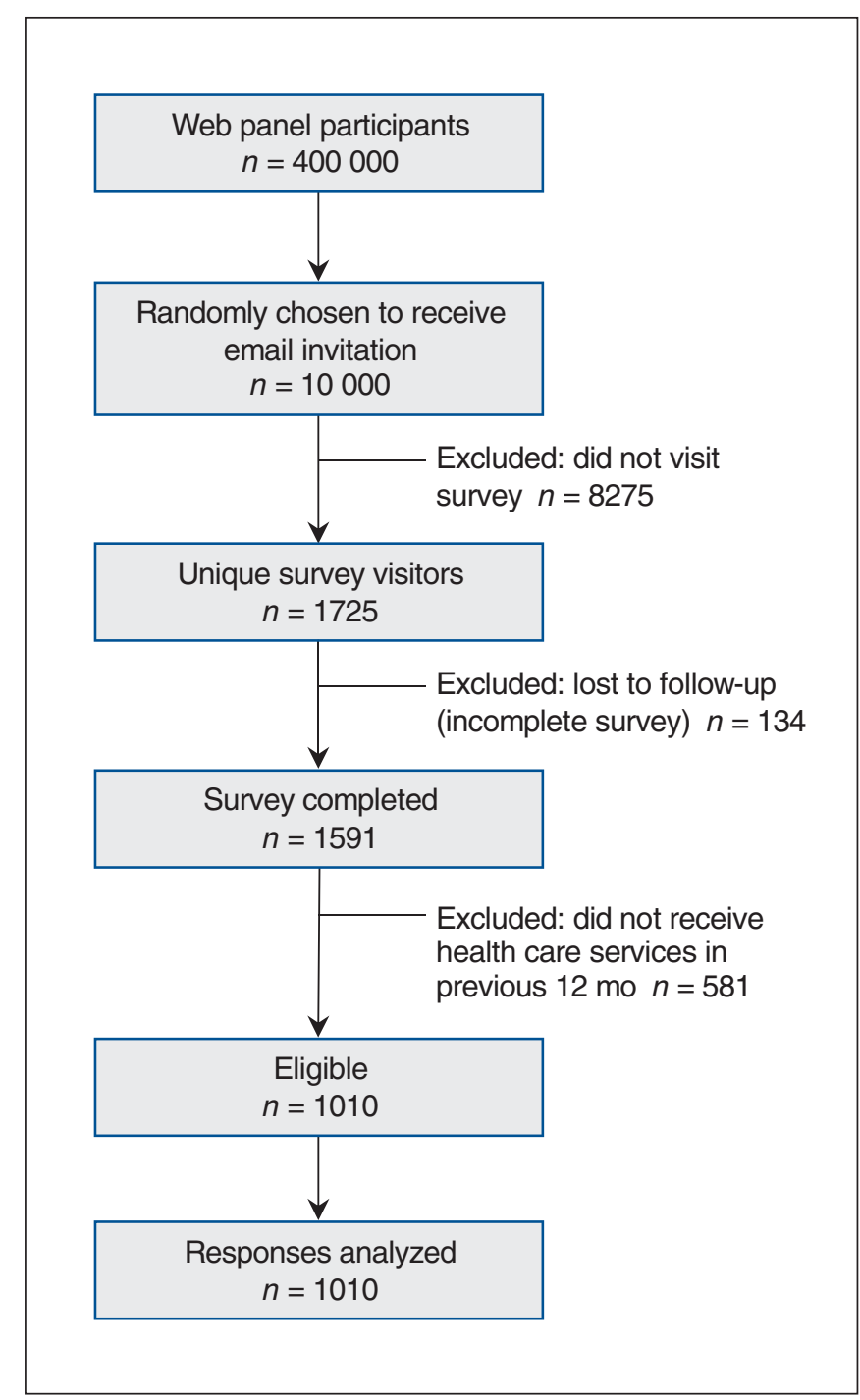

Figure 1: Flow chart showing selection of participants.

\section{Reported degree of shared decision-making}

The mean of the average shared decision-making score was 2.25 (standard deviation [SD] 1.16). The median score was 2.4 (interquartile range 1.4-3.0). After weighting, $42.8 \%$ of respondents stated that their health care professional often or always mentioned that they had a choice of treatment or care plan, $45.4 \%$ reported that advantages and disadvantages of the available options were often or always presented, $38.8 \%$ reported they were often or always asked for their ideas and preferences, $40.2 \%$ reported they were often or always asked about their preferred option, and $54.1 \%$ stated that their level of participation in decision-making often or always matched their preferred level (Table 2).

\section{Factors associated with degree of shared decision- making}

In univariate analysis, age and having a member of the household receiving home care were significantly associated with the 5 outcomes and the average score (Appendix 3, available at 
Table 1 (part 1 of 2): Respondents' descriptive sociodemographic characteristics (total weighted $n=1010$ )

\begin{tabular}{|c|c|c|}
\hline \multirow[b]{2}{*}{ Characteristic } & \multicolumn{2}{|c|}{ No. $(\%)$ of respondents } \\
\hline & Unweighted & Weighted* \\
\hline \multicolumn{3}{|l|}{ Age, yr } \\
\hline $18-24$ & $34(3.4)$ & $55(5.4)$ \\
\hline $25-34$ & $131(13.0)$ & $204(20.2)$ \\
\hline $35-44$ & $136(13.5)$ & $134(13.3)$ \\
\hline $45-54$ & $204(20.2)$ & $200(19.8)$ \\
\hline $55-64$ & 231 (22.9) & $179(17.7)$ \\
\hline$\geq 65$ & $274(27.1)$ & $238(23.6)$ \\
\hline \multicolumn{3}{|l|}{ Sex } \\
\hline Male & $492(48.7)$ & $467(46.2)$ \\
\hline Female & $518(51.3)$ & $543(53.8)$ \\
\hline \multicolumn{3}{|l|}{ Marital status } \\
\hline Single & $184(18.2)$ & $214(21.2)$ \\
\hline Married/common-law & $662(65.5)$ & $649(64.2)$ \\
\hline Separated/divorced & $101(10.0)$ & $89(8.8)$ \\
\hline Widowed & $48(4.8)$ & $42(4.2)$ \\
\hline Prefer not to answer & $15(1.5)$ & $16(1.6)$ \\
\hline \multicolumn{3}{|l|}{$\begin{array}{l}\text { Member of household } \\
\text { receiving home care }\end{array}$} \\
\hline Yes & $79(7.8)$ & $90(8.9)$ \\
\hline No & 922 (91.3) & 908 (89.9) \\
\hline Prefer not to answer & $9(0.9)$ & $12(1.2)$ \\
\hline \multicolumn{3}{|l|}{ Geographical area } \\
\hline Urban & $455(45.0)$ & $476(47.1)$ \\
\hline Suburban & $356(35.2)$ & $353(35.0)$ \\
\hline Rural & $190(18.8)$ & $173(17.1)$ \\
\hline $\begin{array}{l}\text { Do not know/prefer not to } \\
\text { answer }\end{array}$ & $9(0.9)$ & $9(0.9)$ \\
\hline \multicolumn{3}{|l|}{ Ethnicity } \\
\hline White & $861(85.2)$ & $793(78.5)$ \\
\hline Nonwhite & $139(13.8)$ & $199(19.7)$ \\
\hline Declined to answer & $10(1.0)$ & $18(1.8)$ \\
\hline \multicolumn{3}{|l|}{ Level of education } \\
\hline Elementary & $9(0.9)$ & $20(2.0)$ \\
\hline High school & $191(18.9)$ & $277(27.4)$ \\
\hline College & $335(33.2)$ & $310(30.7)$ \\
\hline $\begin{array}{l}\text { University certificate/ } \\
\text { diploma }\end{array}$ & $85(8.4)$ & $68(6.7)$ \\
\hline University & 387 (38.3) & $328(32.5)$ \\
\hline Prefer not to answer & $3(0.3)$ & $8(0.8)$ \\
\hline \multicolumn{3}{|l|}{ Occupation, weighted } \\
\hline Worker & 497 (49.2) & $516(51.1)$ \\
\hline Unemployed & 467 (46.2) & $429(42.5)$ \\
\hline Full-time studies & $30(3.0)$ & $45(4.4)$ \\
\hline Prefer not to answer & $16(1.6)$ & $19(1.9)$ \\
\hline
\end{tabular}

Table 1 (part 2 of 2): Respondents' descriptive sociodemographic characteristics (total weighted $n=1010$ )

\begin{tabular}{|c|c|c|}
\hline \multirow[b]{2}{*}{ Characteristic } & \multicolumn{2}{|c|}{ No. (\%) of respondents } \\
\hline & Unweighted & Weighted $^{*}$ \\
\hline \multicolumn{3}{|l|}{ Total family income, $\$$} \\
\hline$\leq 19999$ & $65(6.4)$ & $85(8.4)$ \\
\hline 20 000-39 999 & $129(12.8)$ & $132(13.1)$ \\
\hline $40000-59999$ & $156(15.4)$ & $169(16.7)$ \\
\hline $60000-79999$ & $147(14.6)$ & $141(14.0)$ \\
\hline $80000-99999$ & $132(13.1)$ & $131(13.0)$ \\
\hline 100 000-124999 & $114(11.3)$ & $97(9.6)$ \\
\hline 125 000-149999 & $60(5.9)$ & $54(5.3)$ \\
\hline$\geq 150000$ & $83(8.2)$ & $83(8.2)$ \\
\hline Prefer not to answer & $124(12.3)$ & $118(11.7)$ \\
\hline \multicolumn{3}{|l|}{ Province } \\
\hline British Columbia & $92(9.1)$ & $142(14.0)$ \\
\hline Alberta & $69(6.8)$ & $104(10.3)$ \\
\hline Manitoba/Saskatchewan & $68(6.7)$ & $58(5.7)$ \\
\hline Ontario & 335 (33.2) & $335(33.2)$ \\
\hline Quebec & 383 (37.9) & $307(30.4)$ \\
\hline Atlantic provinces & $63(6.2)$ & $65(6.4)$ \\
\hline \multicolumn{3}{|l|}{ First language } \\
\hline French & $375(37.1)$ & $274(27.1)$ \\
\hline English & $524(51.9)$ & $511(50.6)$ \\
\hline Other & $109(10.8)$ & $221(21.9)$ \\
\hline Prefer not to answer & $2(0.2)$ & $5(0.5)$ \\
\hline \multicolumn{3}{|c|}{$\begin{array}{l}\text { *Weighted to Canadian census targets for age, sex, region and language based } \\
\text { on distributions reported in the } 2016 \text { Canadian census. Numbers may not total } \\
1010 \text { in all cases as the weighting process involves approximations; the sum of } \\
\text { approximations may lead to a difference of }+1 \text { or }-1 \text { in the total. }\end{array}$} \\
\hline
\end{tabular}

www.cmajopen.ca/content/7/2/E210/supp1/DC1). Geographical area was significantly associated with the 5 outcomes. Province and first language were each significantly associated with 1 or 2 outcomes. No significant associations were observed for other variables.

In multivariate analysis, variables remaining significantly and independently associated with at least 1 of the 5 items and/or the average score were age, having a member of the household receiving home care, geographical area, province and ethnicity (Table 3). The first 3 variables were the most consistently significant variables across the 6 models. Increased age remained consistently significantly associated with a decrease in the degree of the 5 items and the average score, with participants aged 65 years or more experiencing the least shared decision-making ( $\beta=-0.9$ to -1.1$)$.

\section{Shared decision-making among patients receiving home care}

We analyzed the data for a subgroup of 83 participants for whom a member of the household was receiving home care 
Table 2: Descriptive statistics of shared decision-making outcomes (total weighted $n=1010$ )

\begin{tabular}{|c|c|c|}
\hline \multirow[b]{2}{*}{ Outcome; response } & \multicolumn{2}{|c|}{ No. (\%) of respondents } \\
\hline & Unweighted & Weighted* \\
\hline \multicolumn{3}{|l|}{ Choice discussed } \\
\hline Always & $196(19.4)$ & $193(19.1)$ \\
\hline Often & $235(23.3)$ & $239(23.7)$ \\
\hline Sometimes & $301(29.8)$ & $293(29.0)$ \\
\hline Rarely & $106(10.5)$ & $104(10.3)$ \\
\hline Never & $130(12.9)$ & $134(13.3)$ \\
\hline $\begin{array}{l}\text { Do not know/prefer not to } \\
\text { answer }\end{array}$ & $42(4.2)$ & $46(4.6)$ \\
\hline \multicolumn{3}{|l|}{$\begin{array}{l}\text { Advantages/disadvantages } \\
\text { presented }\end{array}$} \\
\hline Always & $198(19.6)$ & $206(20.4)$ \\
\hline Often & $236(23.4)$ & $253(25.0)$ \\
\hline Sometimes & $262(25.9)$ & $243(24.1)$ \\
\hline Rarely & $140(13.9)$ & $130(12.9)$ \\
\hline Never & $140(13.9)$ & $142(14.1)$ \\
\hline $\begin{array}{l}\text { Do not know/prefer not to } \\
\text { answer }\end{array}$ & $34(3.4)$ & $35(3.5)$ \\
\hline \multicolumn{3}{|l|}{ Asked about ideas/preferences } \\
\hline Always & $168(16.6)$ & $169(16.7)$ \\
\hline Often & $219(21.7)$ & $223(22.1)$ \\
\hline Sometimes & $245(24.2)$ & $245(24.3)$ \\
\hline Rarely & $182(18.0)$ & $177(17.5)$ \\
\hline Never & $157(15.5)$ & $154(15.2)$ \\
\hline $\begin{array}{l}\text { Do not know/prefer not to } \\
\text { answer }\end{array}$ & $39(3.9)$ & $43(4.3)$ \\
\hline \multicolumn{3}{|l|}{ Asked about preferred option } \\
\hline Always & $170(16.8)$ & $173(17.1)$ \\
\hline Often & $224(22.2)$ & $233(23.1)$ \\
\hline Sometimes & $250(24.8)$ & $250(24.8)$ \\
\hline Rarely & $161(15.9)$ & $147(14.6)$ \\
\hline Never & $164(16.2)$ & $163(16.1)$ \\
\hline $\begin{array}{l}\text { Do not know/prefer not to } \\
\text { answer }\end{array}$ & $41(4.1)$ & $43(4.3)$ \\
\hline \multicolumn{3}{|l|}{$\begin{array}{l}\text { Match between preferred and } \\
\text { actual level of participation }\end{array}$} \\
\hline Always & $244(24.2)$ & 256 (25.3) \\
\hline Often & 279 (27.6) & $291(28.8)$ \\
\hline Sometimes & 219 (21.7) & 211 (20.9) \\
\hline Rarely & $142(14.1)$ & $132(13.1)$ \\
\hline Never & $90(8.9)$ & $89(8.8)$ \\
\hline $\begin{array}{l}\text { Do not know/prefer not to } \\
\text { answer }\end{array}$ & $36(3.6)$ & $32(3.2)$ \\
\hline
\end{tabular}

*Weighted to Canadian census targets for age, sex, region and language based on distributions reported in the 2016 Canadian census. Numbers may not total 1010 in all cases as the weighting process involves approximations; the sum of approximations may lead to a difference of +1 or -1 in the total. at the time of the survey and for whom we had complete data. Within this group, increased age was associated with a significant decrease in the level of shared decision-making for all 5 items. In fact, people receiving home care presented the lowest average score in our population sample (mean 1.7 [SD 0.5]).

\section{Interpretation}

In this population survey of Canadians from all 10 provinces who reported that they had received health care in 2017, respondents indicated that they experienced a low degree of shared decision-making, with variations across age, care setting, geographical area, province and ethnicity.

Few population-based surveys reporting shared decisionmaking as perceived by patients are available. A US survey showed an increase in perceived shared decision-making from 4.4 to 5.0 (on a 7-point scale) between 2002 and 2014. ${ }^{18}$ Most published measures of shared decision-making are not population-based but, rather, are based on observation of interactions between patients and health care professionals during clinical encounters. A systematic review of measures using the Observing Patient Involvement in Decision Making (OPTION) instrument showed that, whatever the clinical context, the level of involvement remained low. ${ }^{8}$ However, measuring shared decision-making is complex. Numerous tools have been developed, ${ }^{19-21}$ but they adopt different perspectives and measure a wide variety of constructs. Many methodological challenges remain in shared decision-making measurement. ${ }^{19-22}$

Our results also raise important concerns about disparities in patient involvement in health-related decisions depending on age, jurisdiction and geographical area. The inverse relation observed between age and shared decision-making confirms that older people, particularly those receiving home care, are less likely to be engaged in health care decisions. ${ }^{3,23}$ This is of importance since older people have numerous decisions to make, and these decisions can be complex. Approaches to shared decision-making for these patients should be interprofessional and tailored to their characteristics and preferences, and should include informal caregivers. ${ }^{24}$ People living in rural areas and nonwhite people were also less involved in healthrelated decisions. These results call for increased consideration of vulnerable populations, who would most benefit from engaging in shared decision-making., ${ }^{3,18,23,25}$ Shared decisionmaking is an opportunity to decrease inequities, ${ }^{26}$ but we have to ensure that its implementation does not increase them instead, as suggested by our results. Living in Quebec was also associated with less shared decision-making compared to living in the other provinces. This may be partly explained by disparities in initiatives that support implementation of shared decision-making by the different provincial health care systems. ${ }^{26}$ It may also be due to the fact that shared decisionmaking has evolved mostly in English-speaking jurisdictions. ${ }^{16}$

\section{Limitations}

Our study has a few limitations. First, our results are based on participants' recollections about the health care they had 


\begin{tabular}{|c|c|c|c|c|c|c|}
\hline Variable & \multicolumn{6}{|c|}{ Item; $\beta(95 \% \mathrm{Cl})$} \\
\hline $18-24$ & Reference & Reference & Reference & Reference & Reference & Reference \\
\hline $25-34$ & $\begin{array}{c}-0.47 \\
(-0.83 \text { to }-0.1)\end{array}$ & $\begin{array}{c}-0.41 \\
(-0.86 \text { to } 0.04)\end{array}$ & $\begin{array}{c}-0.61 \\
(-1.05 \text { to }-0.17)\end{array}$ & $\begin{array}{c}-0.42 \\
(-0.92 \text { to } 0.07)\end{array}$ & $\begin{array}{c}-0.43 \\
(-0.97 \text { to } 0.12)\end{array}$ & $\begin{array}{c}-0.46 \\
(-0.9 \text { to }-0.01)\end{array}$ \\
\hline $35-44$ & $\begin{array}{c}-0.69 \\
(-1.1 \text { to }-0.29)\end{array}$ & $\begin{array}{c}-0.56 \\
(-1.04 \text { to }-0.09)\end{array}$ & $\begin{array}{c}-0.86 \\
(-1.32 \text { to }-0.40)\end{array}$ & $\begin{array}{c}-0.60 \\
(-1.12 \text { to }-0.08)\end{array}$ & $\begin{array}{c}-0.69 \\
(-1.25 \text { to }-0.12)\end{array}$ & $\begin{array}{c}-0.76 \\
(-1.23 \text { to }-0.30)\end{array}$ \\
\hline$\geq 65$ & $\begin{array}{c}-0.90 \\
(-1.26 \text { to }-0.54)\end{array}$ & $\begin{array}{c}-0.80 \\
(-1.23 \text { to }-0.37)\end{array}$ & $\begin{array}{c}-1.14 \\
(-1.57 \text { to }-0.72)\end{array}$ & $\begin{array}{c}-0.84 \\
(-1.33 \text { to }-0.34)\end{array}$ & $\begin{array}{c}-0.90 \\
(-1.44 \text { to }-0.35)\end{array}$ & $\begin{array}{c}-0.81 \\
(-1.23 \text { to }-0.38)\end{array}$ \\
\hline \multicolumn{7}{|l|}{$\begin{array}{l}\text { Member of household } \\
\text { receiving home care }\end{array}$} \\
\hline No & Reference & Reference & Reference & Reference & Reference & Reference \\
\hline Yes & $\begin{array}{c}0.45 \\
(0.15 \text { to } 0.75)\end{array}$ & $\begin{array}{c}0.44 \\
(0.1 \text { to } 0.78)\end{array}$ & $\begin{array}{c}0.49 \\
(0.13 \text { to } 0.85)\end{array}$ & $\begin{array}{c}0.50 \\
(0.16 \text { to } 0.84)\end{array}$ & $\begin{array}{c}0.45 \\
(0.11 \text { to } 0.78)\end{array}$ & $\begin{array}{c}0.37 \\
(0.03 \text { to } 0.70)\end{array}$ \\
\hline \multicolumn{7}{|l|}{ Geographical area } \\
\hline Urban & Reference & Reference & Reference & Reference & Reference & Reference \\
\hline Suburban & $\begin{array}{c}-0.14 \\
(-0.33 \text { to } 0.05)\end{array}$ & $\begin{array}{c}-0.16 \\
(-0.38 \text { to } 0.05)\end{array}$ & $\begin{array}{c}-0.12 \\
(-0.34 \text { to } 0.10)\end{array}$ & $\begin{array}{c}-0.13 \\
(-0.34 \text { to } 0.08)\end{array}$ & $\begin{array}{c}-0.14 \\
(-0.36 \text { to } 0.08)\end{array}$ & $\begin{array}{c}-0.13 \\
(-0.34 \text { to } 0.07)\end{array}$ \\
\hline Alberta & $\begin{array}{c}-0.19 \\
(-0.61 \text { to } 0.24)\end{array}$ & $\begin{array}{c}-0.10 \\
(-0.60 \text { to } 0.40)\end{array}$ & $\begin{array}{c}-0.16 \\
(-0.67 \text { to } 0.34)\end{array}$ & $\begin{array}{c}-0.36 \\
(-0.84 \text { to } 0.12)\end{array}$ & $\begin{array}{c}-0.01 \\
(-0.48 \text { to } 0.47\end{array}$ & $\begin{array}{c}-0.32 \\
(-0.79 \text { to } 0.15)\end{array}$ \\
\hline $\begin{array}{l}\text { Manitoba/ } \\
\text { Saskatchewan }\end{array}$ & $\begin{array}{c}-0.08 \\
(-0.48 \text { to } 0.32)\end{array}$ & $\begin{array}{c}0.04 \\
(-0.42 \text { to } 0.50)\end{array}$ & $\begin{array}{c}0.00 \\
(-0.47 \text { to } 0.48)\end{array}$ & $\begin{array}{c}-0.19 \\
(-0.71 \text { to } 0.32\end{array}$ & $\begin{array}{c}-0.09 \\
(-0.57 \text { to } 0.39)\end{array}$ & $\begin{array}{c}-0.15 \\
(-0.57 \text { to } 0.28)\end{array}$ \\
\hline Ontario & $\begin{array}{c}-0.20 \\
(-0.50 \text { to } 0.11)\end{array}$ & $\begin{array}{c}-0.08 \\
(-0.44 \text { to } 0.27)\end{array}$ & $\begin{array}{c}-0.06 \\
(-0.43 \text { to } 0.31)\end{array}$ & $\begin{array}{c}-0.34 \\
(-0.72 \text { to } 0.05)\end{array}$ & $\begin{array}{c}-0.19 \\
(-0.56 \text { to } 0.18)\end{array}$ & $\begin{array}{c}-0.31 \\
(-0.65 \text { to } 0.03)\end{array}$ \\
\hline Quebec & $\begin{array}{c}-0.29 \\
(-0.60 \text { to } 0.02)\end{array}$ & $\begin{array}{c}0.07 \\
(-0.28 \text { to } 0.42)\end{array}$ & $\begin{array}{c}-0.19 \\
(-0.55 \text { to } 0.18)\end{array}$ & $\begin{array}{c}-0.38 \\
(-0.77 \text { to } 0.01)\end{array}$ & $\begin{array}{c}-0.40 \\
(-0.78 \text { to }-0.01)\end{array}$ & $\begin{array}{c}-0.55 \\
(-0.9 \text { to }-0.21)\end{array}$ \\
\hline \multicolumn{7}{|l|}{ Ethnicity } \\
\hline Nonwhite & Reference & Reference & Reference & Reference & Reference & Reference \\
\hline White & $\begin{array}{c}0.21 \\
(-0.03 \text { to } 0.45)\end{array}$ & $\begin{array}{c}0.12 \\
(-0.15 \text { to } 0.40)\end{array}$ & $\begin{array}{c}0.24 \\
(-0.03 \text { to } 0.51)\end{array}$ & $\begin{array}{c}0.13 \\
(-0.14 \text { to } 0.41)\end{array}$ & $\begin{array}{c}0.19 \\
(-0.08 \text { to } 0.46)\end{array}$ & $\begin{array}{c}0.37 \\
(0.09 \text { to } 0.64)\end{array}$ \\
\hline
\end{tabular}

received over the previous 12 months; thus, our data may have been subject to recall bias. Second, the response rate was low. This is an inherent limitation to this type of survey, designed to respond quickly to client questions. Participants were given only 3 days to complete the survey once they received the invitation, no reminders were sent, and there was no possibility of relaunching the survey. Third, characteristics of panel members and respondents may not be representative of the majority of Canadians, notably owing to the fact that the territories were not included. Given the small number of respondents, we grouped certain categories of demographic data together (i.e., ethnicity and province), resulting in a loss of data. This may have been exacerbated by the snowball sampling used to constitute the panel. However, we applied 
weighting on major sociodemographic characteristics to correct for potential selection bias. Fourth, our assessment of shared decision-making by means of a population-based survey required using a limited number of items to address a wide range of medical decisions and individual situations. We countered this issue by targeting only essential components of shared decision-making ${ }^{16}$ and focused on the perspective of patients for 1 type of decision. Finally, we had no details on the decision participants were reflecting on, such as the type of health care professional or the health condition.

\section{Conclusion}

Shared decision-making is an ethical imperative, and there is strong evidence supporting it. Yet our results suggest that Canadians experienced a low degree of shared decisionmaking in 2017, with variations across sociodemographic factors, jurisdictions, care settings and geographical areas. Further efforts are needed to foster implementation of shared decision-making in daily clinical practice in Canada and should take these variations into account. Efforts to increase shared decision-making among the most vulnerable members of the population should be a priority.

\section{References}

1. O'Connor AM, Drake ER, Wells GA, et al. A survey of the decision-making needs of Canadians faced with complex health decisions. Health Expect 2003;6: 97-109.

2. Feemster LC, Curtis JR. "We understand the prognosis, but we live with our heads in the clouds": understanding patient and family outcome expectations and their influence on shared decision making. Am 7 Respir Crit Care Med 2016;193:239-41.

3. Légaré F, Witteman HO. Shared decision making: examining key elements and barriers to adoption into routine clinical practice. Health Aff (Millwood) 2013;32:276-84.

4. Weston WW. Informed and shared decision-making: the crux of patientcentered care. CMA7 2001;165:438-9.

5. Stiggelbout AM, Van der Weijden T, De Wit MP, et al. Shared decision making: really putting patients at the centre of healthcare. BMF 2012;344:e256.

6. Légaré F, Ratté S, Gravel K, et al. Barriers and facilitators to implementing shared decision-making in clinical practice: update of a systematic review of health professionals' perceptions. Patient Educ Couns 2008;73:526-35.

7. Légaré F, Thompson-Leduc P. Twelve myths about shared decision making. Patient Educ Couns 2014;96:281-6.

8. Couët N, Desroches S, Robitaille H, et al. Assessments of the extent to which health-care providers involve patients in decision making: a systematic review of studies using the OPTION instrument. Health Expect 2015;18:542-61.

9. Scholl I, LaRussa A, Hahlweg P, et al. Organizational- and system-level characteristics that influence implementation of shared decision-making and strategies to address them - a scoping review. Implement Sci 2018;13:40.

10. Eysenbach G. Improving the quality of Web surveys: the Checklist for Reporting Results of Internet E-Surveys (CHERRIES). 7 Med Internet Res 2004;6:e34.

11. Portrait numérique des foyers québécois. NETendances 2017;8(1). Available: https://cefrio.qc.ca/media/1208/netendances_2017-portrait-numerique-des-foyers -quebecois.pdf (accessed 2018 Nov. 21).

12. Solberg LI, Crain AL, Rubenstein L, et al. How much shared decision making occurs in usual primary care of depression? 7 Am Board Fam Med 2014;27: $199-208$.
13. Wong ST, Chau LW, Hogg W, et al. An international cross-sectional survey on the Quality and Costs of Primary Care (QUALICO-PC): recruitment and data collection of places delivering primary care across Canada. BMC Fam Pract 2015;16:20.

14. Schäfer WL, Boerma WG, Kringos DS, et al. QUALICOPC, a multi-country study evaluating quality, costs and equity in primary care. BMC Fam Pract 2011;12:115.

15. Elwyn G, Edwards A, Kinnersley P, et al. Shared decision making and the concept of equipoise: the competences of involving patients in healthcare choices. Br7 Gen Pract 2000;50:892-9.

16. Makoul G, Clayman ML. An integrative model of shared decision making in medical encounters. Patient Educ Couns 2006;60:301-12.

17. Shina M, Bleakney A. Receiving care at home. Spotlight on Canadians: results from the General Social Survey series. Ottawa: Statistics Canada; 2014. Cat no 89-652-X - no. 002. Available: https://www150.statcan.gc.ca/n1/pub/89-652 -x/89-652-x2014002-eng.htm (accessed 2018 Nov. 21).

18. Levine DM, Landon BE, Linder JA. Trends in patient-perceived shared decision making among adults in the United States, 2002-2014. Ann Fam Med 2017;15:552-6.

19. Scholl I, Koelewijn-van Loon M, Sepucha K, et al. Measurement of shared decision making - a review of instruments. Z Evid Fortbild Qual Gesundhwes 2011;105:313-24

20. Gärtner FR, Bomhof-Roordink H, Smith IP, et al. The quality of instruments to assess the process of shared decision making: a systematic review. PLoS One 2018;13:e0191747.

21. Bouniols N, Leclère B, Moret L. Evaluating the quality of shared decision making during the patient-carer encounter: a systematic review of tools. $B M C$ Res Notes 2016;9:382.

22. Barr PJ, Elwyn G. Measurement challenges in shared decision making: putting the 'patient' in patient-reported measures. Health Expect 2016;19:993-1001.

23. Chewning B, Bylund CL, Shah B, et al. Patient preferences for shared decisions: a systematic review. Patient Educ Couns 2012;86:9-18.

24. Légaré F, Brière N, Stacey D, et al. Implementing shared decision-making in interprofessional home care teams (the IPSDM-SW study): protocol for a stepped wedge cluster randomised trial. BMF Open 2016;6:e014023.

25. Menear M, Garvelink MM, Adekpedjou R, et al. Factors associated with shared decision making among primary care physicians: findings from a multicentre cross-sectional study. Health Expect 2018;21:212-21.

26. Durand MA, Carpenter L, Dolan H, et al. Do interventions designed to support shared decision-making reduce health inequalities? A systematic review and meta-analysis. PLoS One 2014;9:e94670.

27. Légaré F, Stacey D, Forest PG, et al. Milestones, barriers and beacons: shared decision making in Canada inches ahead. Z Evid Fortbild Qual Gesundhwes $2017 ; 123-124: 23-7$.

Affiliations: Centre de recherche sur les soins et services de première ligne de l'Université Laval, Centre intégré universitaire de santé et de services sociaux de la Capitale-Nationale, and Department of Family Medicine and Emergency Medicine, Faculty of Medicine, Université Laval, Québec, Que.

Contributors: France Légaré conceived the study. France Légaré and Hubert Robitaille contributed to the study design. Jordie Croteau conducted data analysis. Julie Haesebaert drafted the manuscript. All of the authors contributed to data interpretation, critically revised the manuscript for important intellectual content, approved the version to be published and agreed to be accountable for all aspects of the work.

Funding: France Légaré holds a Tier 1 Canada Research Chair in Shared Decision Making and Knowledge Translation. This study was funded by the chair.

Acknowledgement: The authors thank Louisa Blair for assistance with manuscript preparation.

Supplemental information: For reviewer comments and the original submission of this manuscript, please see www.cmajopen.ca/content/7/2/ E210/suppl/DC1. 